\title{
EVANGÉLICOS PROGRESSISTAS NO BRASIL POPULAR ${ }^{1}$
}

\author{
Juliano Spyer ${ }^{2}$
}

Resumo: Este artigo examina a atuação política de dois evangélicos pobres, moradores de um bairro na periferia de Salvador. Evangélicos geralmente são percebidos, fora dos círculos de especialistas em temas da religião, como "mercadores da fé" ou como "fanáticos conservadores". Lideranças evangélicas têm questionado esses estereótipos, mas esse debate ainda acontece em relação a evangélicos de classe média e universitários, que interagem com outros intelectuais de classe média. $\mathrm{O}$ artigo a seguir resulta do convívio cotidiano com evangélicos pobres que, considerando parâmetros como legalização da maconha ou do aborto, seriam enquadrados como conservadores e que, no entanto, atuam politicamente em seu bairro defendendo pautas como de justiça social, empoderamento feminino e combate ao racismo.

Palavras-chave: Cristianismo; Brasil; Política; Subalternos.

LOW INCOME PROGRESSIVE EVANGELICALS IN BRAZIL

Abstract: This article examines the political performance of two poor evangelicals, who live in a lower area on the outskirts of Salvador. Evangelicals are generally perceived, outside the circles of experts on any topic of religion, as "merchants of faith" or as "conservative fanatics." Evangelical leaders have challenged these stereotypes, but this debate still takes place in relation to middle-class and college-educated evangelicals, who interact with other middle-class intellectuals. The following article results from the daily contact with poor evangelicals who, considering parameters such as the legalization of marijuana or abortion, would be

${ }^{1}$ Como citar: SPYER, Juliano. Evangélicos progressistas no Brasil popular. Debates do NER, Porto Alegre, ano 21, n. 39, p. 91-118, 2021.

${ }^{2}$ Doutor pelo programa de Antropologia Digital da University College London, Inglaterra. Atualmente é Head of Human Insights na Behup, trabalhando no desenvolvimento do Voices, uma metodologia que combina etnografia e o uso criativo de novas tecnologias. E-mail: spyer@alumni.usp.br. ORCID: https://orcid.org/0000-0003-0951-5345. 
classified as conservatives and who, however, act politically in their neighborhood defending agendas such as social justice, female empowerment and combating racism.

Keywords: Cristianity; Brazil; Politics; Subaltern.

\section{INTRODUÇÃO}

Este texto dialoga com o artigo "Irmãos contra o império: evangélicos de esquerda nas eleiçóes 2020 no Brasil" de Christina Vital da Cunha que examina evangélicos que atuaram como ativistas, militantes ou candidatos em campanhas eleitorais em 2020. Proponho alguns paralelos aos casos que ela utiliza, como o de cristãos que se identificam como pessoas de esquerda e/ou progressistas, mas cuja atividade política acontece em outros círculos de sociabilidade: ambientes de trabalho, universidades e principalmente em suas igrejas e no convívio com pares evangélicos.

No contexto do cristão evangélico, considerarei "progressista"' ou "de esquerda" como categorias de classificação que descrevem quem desafia normas - inclusive as que não estão escritas -, opinióes, posicionamentos hegemônicos e práticas tradicionais que existem nas igrejas. Por exemplo, no primeiro caso examinado neste artigo, apresento a atuação de um pastor batista que se posiciona publicamente contra o presidente Jair Bolsonaro e que defende o legado do ex-presidente Lula em termos de redução da miséria no país, correndo o risco de sofrer retaliaçóes e perder vantagens dentro da organização. No segundo caso, uma jovem assembleiana enfrenta a desaprovação dos adultos da igreja ao utilizar calças compridas quando a expectativa é o uso de saia, e, em seguida, opta por usar cortes de cabelo que explicitam (em vez de esconder) a condição de afrodescendente.

Registrei esses casos ao longo de 18 meses de pesquisa etnográfica em um bairro localizado no extremo da regiáo metropolitana da cidade de Salvador. Eu e minha família moramos nesse bairro entre abril de 2013 e agosto de 2014 como parte das atividades de um programa de doutorado em 
antropologia social. O objetivo da pesquisa foi registrar as consequências do uso das mídias sociais para brasileiros das camadas populares (Spyer, 2018). Por isso, escolhi uma localidade que, nas últimas quatro décadas, funciona como bairro-dormitório para trabalhadores de baixa renda, principalmente da indústria do turismo na região. Igrejas evangélicas - junto com bares, salóes de cabeleireiro, transporte por ônibus e vans e serviços de moto-táxi, comércio informal, crescimento urbano a partir de ocupaçóes de terras e equipamentos públicos de baixa qualidade - fazem parte do cenário recorrente ao qual chamamos de periferias. Em função da quase onipresença do cristianismo evangélico ${ }^{3}$, representada por dezenas de igrejas com tamanhos variados em um bairro com aproximadamente 15 mil moradores, estabeleci relacionamentos de amizade e confiança com algumas famílias e participei rotineiramente de conversas com essas pessoas e suas famílias e das atividades oferecidas em suas igrejas.

Os casos que examino a seguir dialogam com o artigo de Vital da Cunha oferecendo oportunidades para a comparação e a busca de paralelos em relação aos exemplos que ela apresenta. A autora analisa as performances de atores sociais que estáo no front de campanhas políticas e como diferenças geracionais influenciam essas performances, por exemplo, entre os organizadores da Frente Evangélica Popular (FEP) e do movimento Cristãos Contra o Fascismo (CCF). Ela também estuda como os evangélicos identificados com o campo progressista tratam de raça e gênero.

${ }^{3}$ O Censo de 2010 não traz dados precisos sobre este bairro na medida em que não considera a população migrante que habita as áreas ocupadas ilegalmente. $\mathrm{O}$ número de habitantes, segundo a contabilidade feita por políticos locais para estabelecer o número de eleitores na localidade, indicava que, na época, moravam entre 15 e 20 mil pessoas. Em termos de espaços de culto, a localidade tinha uma igreja católica com lugar para aproximadamente 50 pessoas. Nove terreiros de candomblé estavam localizados dentro ou nas proximidades do bairro. As igrejas evangélicas - algumas com espaço para cerca de 400 participantes - eram mais de 50. Só a Assembleia de Deus local tinha 22 igrejas espalhadas em espaços mais afastados do centro do bairro, para facilitar o acesso.

Debates do NER, Porto Alegre, ano 2 I, N. 39, P. 9 I-I i 8, Jan./Jul. 202 I 
Este texto é baseado nas experiências de pessoas de geraçóes diferentes por seu protagonismo no debate de ideias e na incorporação de práticas entendidas como sendo progressistas e/ou de esquerda. A partir desses casos, examino a importância do acesso à educaçáo básica e a cursos universitários como parte do contexto que favorece a exposição ao pensamento e a práticas que motivam o posicionamento crítico dessas pessoas dentro de suas igrejas e comunidades de fé. Também aponto o valor potencial de se considerar, para aprofundar a análise sobre o tema, a denominaçáo evangélica dos sujeitos e também sua classe social, na medida em que pentecostais tendem a ser majoritariamente das camadas populares e protestantes históricos atuarem predominantemente nas camadas médias e altas da sociedade ${ }^{4}$.

Em termos metodológicos, este artigo é baseado em entrevistas e no convívio contínuo com as pessoas que vivenciaram os eventos e situaçóes relatadas. Esses relacionamentos se mantiveram depois do fim do meu trabalho de campo graças ao uso de serviços como Facebook e WhatsApp. Por isso, trechos das informaçóes apresentadas aqui foram coletadas a partir de diálogos em grupos de Whats App com evangélicos no contexto da campanha presidencial de 2018 até o presente. Os participantes do grupo tiveram acesso ao artigo e aprovaram a utilizaçáo desse material. Os nomes das duas pessoas mencionadas sáo fictícios para preservar suas identidades, especialmente em um contexto delicado do envolvimento de igrejas conhecidas nacionalmente com atividades políticas, partidos políticos e com governantes.

${ }^{4}$ Os dados sobre a condiçáo socioeconômica dos pentecostais, indicando que um terço desse grupo tem renda per capita igual ou inferior a meio salário mínimo (o que corresponde a viver em condição de pobreza aguda), foi registrado por Marcos Alvito, professor do Departamento de História da UFF, no artigo "Nós Contra o Mundo", no Dossiê Evangélicos no Brasil, lançado na edição de dezembro de 2012 da Revista de História do Museu Nacional.

Debates do NER, Porto Alegre, Ano 2 I, N. 39, P. 9 I-I I 8, JAn./Jul. 202 I 


\section{TOMAR NO CU COM A BÊNÇÃO DE DEUS}

Em março de 2021, o Brasil completou um ano da pandemia e a situação do país não dava margem para se especular sobre quando as pessoas voltarão a circular fora de suas casas sem máscaras e retomar o contato social - em reuniōes com amigos e familiares, em ambientes de trabalho ou em relação a consumo -, como aconteceu até o início de 2020. No momento em que termino a redação deste artigo, no fim do mês de março de 2021, a imprensa noticia que aproximadamente $6 \%$ da população tomou a primeira dose da vacina e cerca de $2 \%$ tomou as duas doses necessárias para produzir a imunização contra o vírus da Covid-19. O ex-presidente Lula recuperou o direito político e já se posicionou como pré-candidato do PT para a eleição presidencial de 2022. O ex-juiz Sérgio Moro foi condenado por ter agido com parcialidade durante a operação Lava Jato, e a tensão política aumenta na medida em que o presidente Jair Bolsonaro disputa com alguns governadores a melhor maneira para combater a propagação do Covid e reduzir o impacto do lockdown que leva ao fechamento do comércio.

Nesse contexto, a sociedade cansada pela pandemia prolongada, as consequências do isolamento para a educaçáo de crianças e adolescentes, o aumento dos problemas de saúde mental relacionados ao estresse, ansiedade e depressão, o número crescente de mortos e infectados, a frustração que atinge principalmente os brasileiros desempregados pela queda de rendimento e pela alta dos preços de produtos e serviços, e a tensão provocada pelo impacto das medidas de isolamento para o consumo, reavivaram grupos de apoiadores do presidente a fazer manifestaçóes contra o fechamento do comércio ${ }^{5}$. A mensagem a seguir dialoga com essas manifestaçóes:

${ }^{5}$ Cidades Registram Manifestações Pró-Bolsonaro e Contra Medidas De Restrição à Covid-19. G1, 14 Mar. 2021.Disponível em: g1.globo.com/politica/noticia/2021/03/14/ cidades-registram-manifestacoes-pro-bolsonaro-e-contra-medidas-de-restricao-a-covid-19. ghtml. Acesso em: 17 abr. 2021.

Debates do NER, Porto Alegre, ano 2 I, N. 39, P. 9 I-I i 8, Jan./Jul. 202 I 
"Sou pastor evangélico, discípulo de Jesus, e é com consciência tranquila, plena paz no coração, no auge de minha espiritualidade, e em nome de Jesus, que mando todos os que participaram das manifestaçóes hoje irem tomar bem no centro, do meio, do olho do cu. Deus abençoe."

A mensagem foi publicada em 14 de março no Twitter por um dos ativistas mencionados no artigo de Vital da Cunha, o pastor Berlofa. Ele se apresenta pela "bio" de sua conta no Twitter como pastor, escritor, progressista, filósofo, fă do grupo de rap Racionais MC's e apreciador de cerveja.

Morei no bairro onde fiz minha pesquisa de campo durante 18 meses e dediquei muitas horas semanais visitando famílias evangélicas e participando regularmente de cultos. Nesse tempo e em todos os encontros, em conversas privadas, presenciais ou pela internet eu nunca ouvi um evangélico, de qualquer idade, falar sobre política dessa forma. Eu nunca presenciei esse tipo de performance entre evangélicos com quem convivi durante a pesquisa - que propositalmente associa à condição de evangélico um tipo de prática que a sociedade em geral não espera de evangélicos - publicamente ou em conversas privadas, presencialmente ou em conversas em redes sociais.

Isso sugere que os evangélicos estudados por Vital da Cunha não são apenas progressistas e/ou de esquerda, mas têm títulos universitários que os credenciam como brasileiros das camadas médias ou altas - mesmo aqueles que fizeram essa transição via acesso a cursos universitários, uma alternativa que se popularizou recentemente para os brasileiros das camadas populares. Suas audiências também são de pessoas das camadas médias e altas. Em contrapartida, este artigo registra casos de evangélicos das camadas populares e/ou que convivem em bairros populares e que, por isso, representam o evangélico morador das periferias que se mantém fiel ao presidente Bolsonaro depois de 12 meses de pandemia ${ }^{6}$.

${ }^{6}$ Segundo pesquisa realizada em março de 2021 pelo instituto DataFolha, "[A aprovação de Bolsonaro] é maior também entre quem ganha de 2 a 5 salários mínimos (35\% de ótimo e bom) e no nicho evangélico (37\%), que perfaz $24 \%$ da população ouvida.” (Gielow, Igor. Datafolha: Rejeição a Bolsonaro Na Gestão Da Pandemia Bate Recorde 
Os evangélicos de quem vou falar nesta réplica também têm curso universitário e pertencem a gerações e a linhagens evangélicas diferentes. $\mathrm{O}$ pastor Heleno (nome fictício) tinha aproximadamente 38 anos na época em que nos conhecemos, se converteu ao protestantismo durante a juventude, estudou teologia e atua como pastor e funcionário público. Jéssica (nome fictício) estava cursando psicologia em uma universidade privada, frequentada principalmente por estudantes de baixa renda. Ela tinha 26 anos. Seus pais se conheceram na igreja e Jéssica cresceu frequentando a Assembleia de Deus.

\section{CONTEXTO: A DISPONIBILIDADE DE ESCOLAS ANTES E AGORA}

Não cabe estender este texto oferecendo uma apresentação detalhada do bairro onde eu conheci e convivi com Heleno e Jéssica. Entendo que essa localidade não seja fundamentalmente diferente das periferias de outras cidades brasileiras, principalmente em termos da distância para o centro da cidade (aproximadamente 2 horas de ônibus) e na baixa qualidade da infraestrutura e dos serviços públicos disponíveis à população ${ }^{7}$. Mas mencionarei um aspecto sobre essa localidade que ajudará a entender as diferenças geracionais em termos de atuação política. Refiro-me à transformação radical, durante o curto prazo de dez anos, da oferta de serviços públicos de educação.

Até o final da década de 1980, o bairro dispunha de uma escola com duas salas de aula e professoras sem títulos universitários para atender algumas dezenas de alunos, ofertando os quatro primeiros anos do ensino fundamental. Prosseguir estudando, nesse período, implicava em a família do estudante arcar com os custos diários de transporte e também fornecer o material escolar, inclusive livros e cadernos. Somava-se a isso o custo de

e Vai a 54\%. Folha De S.Paulo, 17 Mar. 2021. Disponível em: www1.folha.uol.com. br/poder/2021/03/datafolha-rejeicao-a-bolsonaro-na-gestao-da-pandemia-bate-recorde-e-vai-a-54.shtml. Acesso em: 17 abr. 2021).

${ }^{7}$ Essa descrição está disponível em Spyer, 2018, cap. 1.

Debates do NER, Porto Alegre, ano 2I, N. 39, P. 9 I-I I 8, JAN./JUl. 202 I 
não ter o filho desempenhando uma tarefa produtiva. A escola mais próxima que oferecia os anos escolares seguintes até o final do ensino médio ficava a $30 \mathrm{Km}$ de distância. Em resumo, esse era um preço alto e que de maneira geral nem era considerado como uma possibilidade para famílias que, por geraçóes, aprendiam suas profissóes como pescadores, pedreiros, marisqueiras, coletores de produtos silvestres, ou faxineiras a partir do convívio com familiares adultos.

Por esses motivos, em 18 meses de pesquisa de campo, conheci apenas três pessoas com mais de 40 anos que tinham diploma do ensino superior, dois eram professores nas escolas locais e um, o pastor Heleno, formado em teologia no seminário batista.

No prazo de 10 anos, entre o fim dos anos 1980 e 1990, a disponibilidade de serviços de educação se transformou pela abertura de três escolas novas, que passaram a oferecer 12 anos de ensino básico na própria localidade, com equipe docente formada em cursos de nível superior. A proibiçáo legal do trabalho até os 16 anos de idade também motivou pais a matricularem seus filhos nas escolas. Gradualmente, o governo incluiu outros benefícios para apoiar famílias com crianças em idade escolar, incluindo o fornecimento do equipamento escolar - cadernos, livros, uniforme -, a disponibilidade de transporte gratuito para buscar e levar estudantes que moram longe das escolas, e a oferta de merenda no intervalo.

Por causa dessas mudanças, durante o período em que estive na localidade, ir para a universidade tinha se tornado algo menos incomum para quem terminasse o ensino médio. E mesmo os jovens que escolhiam não ir para a universidade, tinham melhor treinamento escolar que seus pais e isso trouxe a oportunidade de se candidatarem para vagas de trabalho disponíveis para pessoas que sabiam ler e escrever. Em vez de ocupar cargos manuais como cozinheiros, faxineiras, motoristas, jardineiros, pedreiros e vigias, eles podem atuar como vendedores em lojas, garçons, e funcionários da área administrativa em empresas como supermercados e cartórios.

Heleno chegou ao curso superior porque foi patrocinado por uma família batista, que o identificou como uma criança inteligente e curiosa. 
Mas para a geração seguinte, com a abertura das novas escolas, a possibilidade de obter um diploma universitário se tornou algo tangível para pelo menos uma parte dos moradores do bairro. A maioria dos jovens que, durante a minha pesquisa de campo entre 2013 e 2014 , quiseram e tiveram condiçóes para se tornarem universitários eram evangélicos.

Em resumo, o jovem evangélico chegava com mais frequência à universidade porque, em geral, graças às atividades nas igrejas relacionadas à leitura da Bíblia, tinha melhor desempenho escolar. Além disso, nessa localidade em que atuei como pesquisador, famílias evangélicas geralmente tinham mais condiçóes de ajudar a pagar os gastos com a universidade, e, ainda, porque, no ambiente das igrejas evangélicas, a prosperidade material vem sendo cada vez mais exibida como uma evidência da vitória do religioso sobre os desafios da vida. Poder financiar o curso universitário de uma filha ou filho está entre os itens que indicam a obtenção dessa prosperidade.

\section{DEBATES ENTRE EVANGÉLICOS DURANTE A ELEIÇÃO DE 2018}

Depois do fim da minha pesquisa de campo, o pastor Heleno continuou criando oportunidades para que eu tivesse contato com evangélicos, especialmente durante o período da campanha presidencial de 2018. Eleitor do PT e defensor dos programas sociais postos em andamento durante os governos Lula-Dilma, ele me incluiu em um grupo de WhatsApp formado por pastores batistas da regiáo onde ele e sua família moravam e ele atuava como pastor. Nesse ambiente, Heleno fazia parte de um grupo minoritário entre os participantes que questionava o apoio de cristãos ao entáo candidato Jair Bolsonaro.

A posição que Heleno e alguns outros defendiam apontava para a contradição entre a atuação de Jesus como um pacifista e defensor dos desamparados e a proposta de Bolsonaro sobre a ampliação da venda de armas de fogo, sua admiração por torturadores, e seu apoio para que as 
polícias atuassem de forma mais severa para conter a criminalidade. As perspectivas do pastor Heleno coincidem com as dos participantes da FEB, mencionadas no artigo de Vital da Cunha. Ele se apresenta como uma pessoa "de esquerda" e associa essa identidade à defesa da justiça social e à redução da desigualdade, relacionando diretamente esse tipo de interesse aos exemplos de Cristo registrados na Bíblia.

Acompanhei os debates nesse grupo de WhatsApp ao longo da eleição de 2018. Os argumentos dos evangélicos pró-Bolsonaro usados para defendê-lo incluíam a afirmação de que o PT era um partido corrupto. Eles também mencionavam a questão da chamada "ideologia de gênero" para argumentar que o PT era contra a família tradicional cristã. Falavam sobre os problemas atuais vividos por causa da criminalidade a que a sociedade estava exposta e que o PT era conivente com essa situação, estando mais interessado na proteçáo de contraventores e criminosos do que em prover segurança para a sociedade. Falavam ainda sobre a questão da meritocracia e das liberdades individuais que, na eventual vitória do candidato petista, seriam reduzidas. Em síntese, esse grupo argumentava que, elegendo o candidato petista, o brasileiro que trabalha duro ajudaria a manter os preguiçosos que não querem trabalhar; e a igreja ficaria vulnerável pela redução das liberdades de culto e promoção do ateísmo.

\section{O APOIO DE EVANGÉLICOS A BOLSONARO}

O voto evangélico é considerado por alguns analistas como decisivo para a eleição de Jair Bolsonaro ${ }^{8}$. Dados do instituto DataFolha relacionando

${ }^{8}$ Considerando como votaram os outros grupos religiosos, vários analistas associaram a vitória do conservador Jair Bolsonaro ao apoio de evangélicos. $\mathrm{O}$ antropólogo da Unicamp Ronaldo de Almeida escreveu que "quem fez, de fato, a diferença a favor de Bolsonaro em números absolutos foram os evangélicos” (Almeida, 2019). O doutor em demografia José Eustáquio Diniz Alves, professor titular da Escola Nacional de Ciências Estatísticas (ENCE/IBGE), afirmou: "Não há dúvida de que o voto evangélico foi

Debates do NER, Porto Alegre, Ano 2 I, N. 39, P. 9 I-I I 8, JAn./Jul. 202 I 
religião e voto declarado no segundo turno da eleição de 2018 indicam que cristãos evangélicos foram o único grupo religioso no Brasil a votar majoritariamente a favor de Bolsonaro. Duas a cada três pessoas que se identificaram como evangélico/a disseram ter votado no ex-capitáo.

\begin{tabular}{|lrrr|}
\hline \multicolumn{4}{|c}{$\begin{array}{l}\text { DISTRIBUIÇÃO DO ELEITORADO POR TIPO DE RELIGIÃO, COM CORREÇÃO DOS } \\
\text { DADOS DO DATAFOLHA }\end{array}$} \\
\hline Religião & Votos de Bolsonaro & Votos de Haddad & Diferença \\
\hline Católica & 29795232 & 29630786 & 164446 \\
Evangélica & 21595284 & 10042504 & 11552780 \\
Afro-brasileiras & 312975 & 755887 & -442912 \\
Espírita & 1721363 & 1457783 & 263580 \\
Outra religião & 709410 & 345549 & 363862 \\
Sem religião & 3286239 & 4157381 & -871142 \\
Ateu e agnóstico & 375570 & 691097 & -315527 \\
\hline Total de votos & 57796074 & 47080987 & 10715087 \\
\hline Fonte: Pesquisa Datafolha, 25 out. 2018. & & \\
\hline
\end{tabular}

Recupero esse dado para apresentar o resultado de uma pesquisa que eu conduzi para o Instituto Ideia Big Data, após a contagem dos votos do primeiro turno, por encomenda da revista Época (Portinari, 2018 ${ }^{9}$ ), e que espelha os argumentos apresentados no grupo de WhatsApp mencionado na

fundamental para a eleição de Jair Bolsonaro" (Alves, 2019). Mesmo sendo menos de um terço do eleitorado, as lideranças evangélicas são muito atuantes na política e estão colhendo o resultado de anos de ativismo religioso na sociedade. O sociólogo Marcos Coimbra, presidente do Instituto Vox Populi, afirmou, com o suporte de dados de seu instituto, que não foram os evangélicos como um todo, mas a parcela feminina pobre e evangélica do eleitorado que decidiu a eleição a favor de Bolsonaro. A antropóloga Jacqueline Moraes Teixeira, da USP, chegou a conclusōes semelhantes acompanhando as discussóes sobre política de grupos no WhatsApp de mulheres evangélicas da Igreja Universal durante a eleição (Rossi, 2019).

${ }^{9}$ PORTINARI, Natalia. VÍDEO: Eleitor Evangélico Tem Alta Expectativa Para Governo Bolsonaro. Época, 7 Nov. 2018. Disponível em: epoca.globo.com/video-eleitor-evangelico-tem-alta-expectativa-para-governo-bolsonaro-23211744. Acesso em: 17 abr. 2021

Debates do NER, Porto Alegre, ANo 2 I, N. 39, P. 9 I-I I 8, JAN./Jul. 202 I 
seção anterior, sobre as preferências do eleitor evangélico pela candidatura Bolsonaro.

O estudo ouviu 275 evangélicos residentes em todas as regiôes do país que disseram ter votado em Bolsonaro. Suas respostas foram gravadas em arquivos de vídeo respondendo à questão: "O que eu, como evangélico, espero de Bolsonaro como presidente?” As respostas foram transcritas e comparadas.

Os participantes geralmente mencionaram mais de um motivo para votar em Bolsonaro. Dado que a finalidade da pesquisa era a publicação de um artigo em uma revista semanal, argumentos semelhantes foram consolidados em uma fala escrita na primeira pessoa. Os leitores foram informados sobre essa decisão metodológica na apresentação da matéria e tinham também, na versão online do artigo, um documento em áudio - devidamente anonimizado - para comparar com as versóes escritas.

Os argumentos que apareceram com maior regularidade foram os seguintes:

\section{I) UM VOTO DE CONFIANÇA}

"Antes de qualquer coisa, eu espero que o Bolsonaro cumpra com as promessas que ele fez para mudar e melhorar o país. Todo mundo pode prometer, mas cumprir é mais difícil. Precisamos de alguém que faça a diferença para os brasileiros acreditarem que é possível mudar. Que ele não seja mais um político a roubar o Brasil. Espero que ele seja o início da solução. A gente deseja tudo, mas é esperar para ver. O que vier de mudança a gente aceita."

\section{2) ACABAR COM A CORRUPÇÃO}

"Espero que ele cumpra a promessa de colocar ordem na casa acabando com a corrupção, com a demagogia e com a ladroagem. Que ele seja bem conservador nessa questão da corrupção, que prejudica muito. Muitos dizem que ele é radical, mas é pior a gente apoiar candidato que está envolvido 
com a Lava Jato. Tem coisas que o Bolsonaro diz que eu não concordo, mas o PT está lá há muito tempo. Às vezes, arriscando, as coisas podem mudar."

\section{3) FAMÍLIA TRADICIONAL}

"Que o Bolsonaro preze e olhe pelos anseios da família tradicional e não permita a aprovação de leis que sejam contra a moral e os valores cristãos. $\mathrm{O}$ PT defende legalizar o aborto e a venda de drogas. Espero que o Bolsonaro, sendo eleito, não deixe mais que a opinião da minoria se sobreponha à da maioria. O Brasil está muito liberal. Que ele possa nos ajudar a controlar essa liberalidade."

\section{4) KIT GAY E IDEOLOGIA DE GÊNERO}

"Espero que no governo dele acabe com essa história de ideologia de gênero nas escolas, para os nossos filhos não terem que aprender que ser menino ou menina é uma escolha. $\mathrm{O}$ 'kit gay' não é correto, ainda mais para crianças de cinco, seis anos. Há muita sexualidade nas escolas hoje e a inocência das crianças deve ser preservada. Os alunos já estudam as questóes corporais e sexuais nas aulas de biologia. É o suficiente. Que a pessoa decida sobre a sexualidade dela quando for adulta.”

\section{5) ESCOLA MILITAR}

"Por falar em educação, é legal a ideia dele da escola militar. Quem não depende de escola pública, não sabe como é. Escola é para estudar e não para usar droga. Os jovens estão muito destemidos, muito indisciplinados. É bem-vindo o Bolsonaro ser um conservador e defender um sistema que impóe limites ao jovem.”

\section{6) VIOLÊNCIA, SEGURANÇA}

"Aqui na região que eu moro a crise pegou e hoje a gente está preso dentro de casa. É impossível ter um negócio, um carro, um telefone, e as 
crianças passam o dia expostas ao crime e à impunidade. Está muito perigoso. Lugar de bandido é na cadeia. Tolerância zero! Que o Bolsonaro acabe com o que existe de errado nas esquinas: a bandidagem, as facçóes, maconheiro, trombadinha. E diminua a maioridade penal para 16 anos.”

\section{7) CRISE, DESEMPREGO}

"Eu fui uma das pessoas que perderam o emprego. A gente não aguenta mais a crise. Em vez de liberar arma, por que o Bolsonaro não libera emprego? Espero que ele melhore a economia, diminua impostos, organize as contas públicas, tire o país da recessão, dê oportunidade aos jovens e faça o Brasil prosperar. Que todos possam sustentar suas famílias e conquistar seus sonhos."

\section{8) POLÍTICA E RELIGIÃO}

"Que os cristãos tenham as mesmas liberdades que temos hoje e que o evangelho possa continuar a ser pregado livremente. Que a gente possa expressar as nossas opinióes em público sem riscos. Mas tem que melhorar o país independente do credo. Não podemos misturar política e religião. $\mathrm{O}$ amor ao próximo não é apenas para quem tem a mesma religião que eu. Estou com fé, por ele ser cristão, que Deus vai honrar e ajudar ele a fazer uma boa gestão. A Bíblia diz que quando o justo governa, o povo se alegra."

\section{EVANGÉLICOS CONTRA BOLSONARO}

Mais recentemente, o pastor Heleno me incluiu em um grupo novo no Whats $A p p$ que reúne pastores críticos ao governo Bolsonaro. Nesse grupo, bastante ativo e com 34 participantes, todos homens, compartilha-se conteúdos como o texto: "O que a psicopatologia nos ensina sobre não argumentar com bolsominions”, creditado à professora Vera Amaral, Psiquiatra, da UFRN. Em relação à notícia de que o pastor Silas Malafaia havia testado positivo para o Covid-19, um dos participantes do grupo 
escreveu: "Não precisa de oraçóes quem tem hidroxicloroquina, ivermectina e o mito..." Em outra postagem, um participante compara: "recomendar medicamento sem eficácia comprovada cientificamente para o tratamento profilático de Covid-19 é o mesmo que recomendar para as pessoas receber o diabo no coração para serem salvas".

As críticas políticas geralmente são feitas a partir de argumentos religiosos e também por meio de humor. Um meme compartilhado no grupo na véspera da Páscoa de 2021 diz: "Comer carne na Semana Santa já não é pecado, é milagre”, fazendo referência ao aumento do preço dos alimentos relacionado à pandemia. Há referências diretas também a autores marxistas, como o italiano Antonio Gramsci, creditado como autor da frase: "Um velho mundo agoniza, um novo mundo tarda a nascer, e nesse claro-escuro irrompem os monstros". O tema racial também aparece na troca de mensagem a partir do uso de emoticons com máos e rostos de pessoas negras.

Perguntei para os participantes desse grupo qual era o entendimento deles sobre ser "evangélico progressista". As respostas que chegaram foram:

- "Ser progressista pra mim, é o que muitos equivocadamente chamam de liberal. É alguém que está aberto a dialogar e discutir questóes de 'mundo' e 'vida' contextualizada ao seu tempo e grupo. Como diz [o teólogo suíço Karl] Barth: 'ler jornal do dia e ter Bíblia na mão'”

- "É pautar as questóes sociais em torno da manutenção da vida humana e da vida em si usando a Escritura, de olho nas camadas menos favorecidas, com menos voz e menos dinheiro, e ser parceiro deles para que eles tenham voz também para existir. Não tem, necessariamente, nada a ver com Marx, mas com Jesus de Nazaré e a sua interpretação encarnada do Javismo.”

- "Ser cristão progressista do ponto de vista dos batistas é ter liberdade de consciência, de pensamento, ter a possibilidade de se expressar e de não ser rechaçado ao emitir uma crítica a um modelo político, a um governo, ao fundamentalismo radical." 
Este último argumento chegou acompanhado de um link apontando para uma página do site da Convençáo Batista Brasileira $(\mathrm{CBB})^{10}$ mencionando a lista de princípios consagrados entre os batistas, para destacar os princípios de número 2 e 3 , que reproduzo a seguir:

2 - Sua competência - O indivíduo, porque criado à imagem de Deus, torna-se responsável por suas decisóes morais e religiosas.

3 - Sua liberdade - Os Batistas consideram como inalienável a liberdade de consciência, a plena liberdade de religiäo de todas as pessoas.

Esses dois princípios foram mencionados em relaçáo à experiência, relatada anteriormente pelo pastor Heleno, de que havia e há entre batistas açóes - explícitas ou veladas - para intimidar os pastores que não concordam e defendem a presidência de Jair Bolsonaro, segundo os argumentos apresentados nas seçōes anteriores.

\section{A INFLUENNCIA DAS IGREJAS NO POSICIONAMENTO POLÍTICO DOS PASTORES}

No início de 2021, esse grupo de pastores anti-bolsonaristas me convidou para fazer uma apresentação do livro que escrevi sobre cristianismo evangélico no Brasil. Depois da minha exposiçáo, fiquei com a impressão, a partir do relato deles, de que evangélicos pentecostais davam apoio mais enfático ao governo Bolsonaro, e que pastores de igrejas protestantes históricas em geral tinham um posicionamento diferente ou, pelo menos, suas igrejas náo interferiam na posição dos pastores. Ao pedir esclarecimento sobre esse ponto para os participantes do grupo, ouvi respostas que contradiziam a hipótese sobre pentecostais serem os principais apoiadores do governo Bolsonaro.

${ }^{10}$ Disponível em: http://www.convencaobatista.com.br/siteNovo/pagina.php?MEN_ID=21. Acesso em: 17 abr. 2021.

Debates do NER, Porto Alegre, Ano 2 I, N. 39, P. 9i-I i 8, Jan./Jul. 202 I 
Conforme um dos participantes do grupo explicou: "A questão não é, a meu ver, sobre nossa eclesiologia. É sobre nossa consciência de classe social. Não depende da denominação nem de sua tradição histórica de fé. Depende mesmo da sua consciência. Para alguns, a denominação pode até tentar castrar sua consciência, mas ele sabe quem é e de onde veio. A denominação às vezes liberta, por outra aprisiona. Os Batistas, tal qual os assembleianos, são libertadores e opressores. Não nessa ordem, necessariamente!”

Outro participante do grupo concordou parcialmente com a percepção sobre pentecostais serem mais claramente pró-governo: "Quando adentramos a questão política de uma forma mais específica, percebo que os pentecostais (especialmente os assembleianos) são mais pró-governo. A pressão da liderança pentecostal é bem mais indutiva, neste sentido, do que os batistas por exemplo. Mesmo que alguns líderes batistas se posicionem pró-governo, a sua ação é limitada por uma questão de princípios.” Mas, em seguida, esse participante indica que também dentro da igreja batista histórica acontece a pressão para apoiar o governo e as intimidaçóes que sugerem que os não-alinhados serão prejudicados: "A minha crítica severa está justamente aí, vejo um número significante de pastores batistas agindo contra os princípios consagrados entre os batistas [de que cada pessoa tem liberdade de consciência]."

Perguntei para os participantes do mesmo grupo se eles sentiram, durante a campanha presidencial de 2018, um clima de intimidação explícita ou velada sobre quem não estava alinhado com a promoção de votos a favor de Bolsonaro.

A resposta de um dos participantes foi que: "Sim, e agora mais acentuado ainda! E vai continuar. Nosso sistema [batista] de 'autonomia das igrejas' não favorece o pastor. Não que eu seja contra. A liberdade Batista é o que nos caracteriza. Às vezes eu sinto que no nosso caso os pastores acabam se vendo como concorrentes [porque podem ser demitidos de suas funçóes pela congregação]." Ele conclui comparando a posição dos batistas em relação à igreja presbiteriana, indicando que o pastor batista é mais livre, mas fica mais exposto à retaliação dos colegas. "No presbiterianismo não há espaço 
para a pluralidade. Tanto é que poucos pastores presbiterianos têm pensamentos diferentes, porém os pastores são cuidados pelo presbitério. Eles fecham contratos de $\mathrm{X}$ anos com a igreja. Após esse tempo, a igreja renova ou não. Se ele sai e não tem uma igreja, o presbitério cuida dele com um teto salarial, inclusive todos eles têm um teto salarial."

Esses argumentos refletem as conclusóes apresentadas pelo antropólogo Ronaldo de Almeida apresentadas no paper apresentado como parte da série Brazil Today da Universidade de Princeton, intitulado "A Religião de Bolsonaro". Almeida (2020) argumenta que a religião do governo atual é formada por cristãos conservadores, e não especificamente por evangélicos pentecostais reconhecidos, por exemplo, na figura da Ministra Damares Alves. A composição do alto escalão do governo exemplifica que católicos e protestantes históricos estão presentes em cargos importantes. Evangélicos pentecostais aparecem com destaque, mas grupos conservadores representantes de outras tradiçóes também dão sustentação ao governo, conforme sugerem os relatos mencionados nessa seção por pastores batistas que se referem a situaçóes em que são intimidados, constrangidos e ameaçados em suas organizaçôes por rejeitarem a posição hegemônica de apoio ao presidente.

\section{LONGE DA IGREJA E PERTO DOS AMIGOS}

Relatarei a seguir um caso etnográfico sobre eventos que aconteceram na Assembleia de Deus que eu frequentei; casos que classifico como sendo políticos, no sentido abrangente da palavra, das relaçóes de poder entre indivíduos e grupos. Estes casos devem ser examinados considerando as mudanças na disponibilidade de serviços educacionais, pela ampliação da oferta de quatro para doze anos de ensino público no bairro, pela consequência dessa mudança para famílias evangélicas, que em geral têm - comparativamente a seus vizinhos - mais recursos financeiros e incentivam seus filhos a buscar diploma em curso superior, e pelas possibilidades novas de comunicação nas camadas populares a partir de meados dos anos 2000 com o surgimento de 
lan houses para acesso a serviços de redes sociais como Orkut e, posteriormente, Facebook e WhatsApp.

As três estudantes universitárias que trabalharam comigo como assistentes de pesquisa eram evangélicas da Assembleia de Deus e estudavam psicologia e pedagogia. Uma dessas estudantes, que vou chamar pelo nome fictício de Jéssica, conseguiu ser aprovada no curso de Letras na Universidade Federal da Bahia, mas desistiu depois de um ano por causa do alto custo de vida, bancado por sua família, para permanecer em Salvador. Outro motivo da desistência, relatado por ela, foi a sensaçáo de ser rejeitada, entre outras coisas, por sua identidade de brasileira das camadas populares e evangélica pelos outros estudantes advindos das camadas médias. Depois de abandonar a vaga na UFBA, a estudante entrou em uma universidade privada com perfil de alunos semelhante ao dela, do ponto de vista socioeconômico.

Localizada em bairros distantes das áreas mais centrais e abastadas da cidade, essa universidade privada também reduzia os gastos de Jéssica com alojamento e alimentação, já que ela podia continuar vivendo na casa dos pais, e usar o transporte gratuito oferecido pelo governo para estudantes universitários. Além de estar em um ambiente universitário mais acolhedor, ao lado de estudantes com histórias familiares parecidas com a dela, Jéssica também mencionou como aspecto positivo ter conseguido um ambiente de socialização distante do de seu bairro. No bairro todos os moradores se conhecem direta ou indiretamente, e isso limitava suas possibilidades de estabelecer relacionamentos considerados "impróprios" como, por exemplo, se tornar amigo ou amiga de uma pessoa que não fosse evangélico/a. A universidade era um local afastado onde ela poderia finalmente se aproximar de pessoas que ela considerava interessantes, mesmo que não fossem evangélicas.

Outro elemento diferenciador para o jovem universitário dessa geração foi a disponibilidade de acesso a mídias sociais via smartphones. Conforme argumento na minha tese de doutorado (Spyer, 2018) - sobre as consequências do uso das mídias sociais para os brasileiros de origem popular -, o smartphone é o primeiro computador efetivamente usado pelo brasileiro de baixa renda de maneira privada. Inicialmente, o acesso à internet acontecia 
exclusivamente por lan houses, que representam um local sem privacidade em que os computadores são compartilhados. As famílias que compraram desktops ou laptops também compartilhavam o uso desses equipamentos, que geralmente ficavam na sala e, portanto, visíveis para os outros moradores da casa e eventuais visitantes.

O smartphone trouxe privacidade de comunicação e, segundo os relatos que eu registrei de conversas com universitários evangélicos, essa mídia permitiu que os vínculos estabelecidos durante os intervalos das poucas horas em que eles se encontravam com seus colegas universitários pudessem ser cultivados à distância de maneira discreta. $\mathrm{O}$ caso de Jéssica é exemplar em relação a esse tema. Diariamente ela saía de casa em torno das quatro horas da tarde e chegava à universidade em torno das seis, na hora do início das aulas. Ela assistia às aulas e retornava para casa imediatamente para não perder o último ônibus que passava em torno das 11 da noite. Essa rotina a privava da experiência, que também faz parte da vida universitária, de convivência fora dos ambientes de sala de aula com seus pares, estudantes de sua classe, da sua e de outras disciplinas.

Jéssica menciona que pôde cultivar esses vínculos com seus pares da universidade via grupos de estudantes criados no Facebook, que conduziam ao estabelecimento de relaçóes diretas com quem ela, então, passava a interagir por meio de comentários em postagens. Conversas em grupos no WhatsApp criados para reunir os alunos de uma sala, entre colegas encarregados de realizar um trabalho em conjunto, até grupos com menos participantes, constituídos por pessoas que se identificavam entre si e formavam vínculos de amizade. Jéssica me explicou que, pelo Facebook, ela podia ter amigos e manter amizades com pessoas envolvidas em movimentos identitários porque ela conseguia estar presente e se manter em diálogo sem ser "policiada” por outros evangélicos de sua igreja. Ela conseguia se manter conectada com os vários "palcos" de sua vida social, e atuar de maneira específica conforme o contexto.

A internet e os canais digitais de comunicação eram tão importantes para esses jovens que ter equipamento, conhecimento e interesse para utilizá-los 
era, em si, critério para se aproximar ou não de pessoas. Conforme Jéssica relatou, uma pessoa de sua idade que não usasse a internet e não desse valor a esse canal de comunicação era um "tabaréu", ou seja, um "caipira", uma pessoa que não era "moderna", sem curiosidade, sem interesse por coisas novas. E ela não tinha interesse em investir nesses relacionamentos ${ }^{11}$.

Eu acompanhei de perto a trajetória de Jéssica e as consequências de sua experiência como estudante universitária, do uso das mídias digitais via smartphones para que ela assumisse posturas críticas em relação a normas e valores mantidos tradicionalmente em sua igreja.

\section{A REVOLTA DA CALÇA JEANS}

Jéssica liderou uma disputa dentro da igreja com o pastor e com outros adultos pelo uso da calça comprida para ir à universidade - contrariando a tradição assembleiana de mulheres usarem sempre saias. $\mathrm{O}$ pastor - e também os pais de Jéssica - classificavam esse ato como indício de que o convívio universitário estava desviando estudantes da vida religiosa. Jéssica desacatou essa norma e mobilizou seu grupo de amigos e amigas na igreja a defenderem sua decisão. Ela argumentava que não havia problemas em continuar seguindo as normas e as tradiçóes da igreja dentro da igreja, mas advogava pelo direito de se vestir de maneira mais sintonizada com seus pares universitários quanto estava no ambiente universitário.

Ela explicou que a motivação para entrar em atrito com os adultos resultou de seu esforço para estabelecer relacionamentos e ser respeitada entre seus pares na universidade, pessoas que ela reconhecia como sendo inteligentes e interessantes. Esses colegas, a princípio, a mantiveram distante por perceberem, pelo uso da saia característica, lisa e com a barra abaixo da

11 O capítulo 2 do meu livro "Mídias Sociais no Brasil Emergente" (2018) apresenta mais detalhadamente esse assunto e como o uso da tecnologia não era desejado apenas pelos adolescentes e jovens com maior escolaridade como Jéssica, mas eram produtos e serviços essenciais para que a pessoa fosse classificada e vista por seus pares como alguém “jovem".

Debates do NER, Porto Alegre, ano 2 I, N. 39, P. 9 I-I i 8, Jan./Jul. 202 I 
altura do joelho, que era evangélica e, por isso, a consideravam uma pessoa submissa, sem capacidade para pensar por si mesma e de fazer frente à visão dos líderes de sua igreja, com valores morais conservadores, que pensava e atuava no mundo a partir dos textos bíblicos, e não da ciência.

Jéssica percebia sua atuação, nesse caso - referente à disputa para usar calça comprida para as atividades na universidade -, como tendo duas frentes. $\mathrm{Na}$ igreja, ela queria mostrar que uma pessoa evangélica não se desvia da fé apenas porque faz universidade, e, na universidade, ela queria mostrar que a imagem do evangélico é estereotipada. Além disso, que era possível alinhar a identidade religiosa, o conhecimento científico e a ambição de ser uma mulher com uma carreira profissional, diferente do trabalho da maioria das outras mulheres da igreja, que eram predominantemente faxineiras ou vendedoras.

A calça comprida, aqui, funcionou como um elemento performático, teatral, para usar a referência teórica escolhida por Vital da Cunha, para negociar sua identidade entre pares na universidade e ser acolhida por eles, e, também, para manter sua rede de afetos, de confiança, e seu prestígio como jovem evangélica moderna dentro da igreja que ela frequentava. Jéssica relatou que não queria se afastar da igreja, pela importância desse aspecto de sua vida, para a manutenção dos vínculos com seus pais, e por entender que uma de suas principais redes de apoio era constituída pelos relacionamentos com pessoas da mesma idade, que cresceram junto com ela participando das atividades na igreja. E foi com o apoio desse grupo, já adulto e articulado, de pares assembleianos, que ela fez frente contra a pressão da tradição do uso de saias em qualquer ocasião.

A experiência vitoriosa de resistir à pressão dos adultos da igreja e seguir usando calças compridas para ir à universidade teve continuidade a partir de outra decisão, também relacionada ao ambiente social da universidade. Para Jéssica, a experiência de fazer parte da comunidade universitária, do ponto de vista social e político, se deu a partir do esforço para formar vínculos de amizade com estudantes militantes do movimento negro e/ou ligados às religióes de matriz afro brasileira. Esses grupos, mais intelectualizados, 
não estavam presentes no bairro em que ela vivia, e, mesmo que houvesse pessoas com esse perfil, o ambiente controlador do bairro, via redes de fofoca e ataque ao prestígio, inviabilizaria que essas amizades acontecessem.

\section{CONSCIÊNCIA RACIAL E PRODUTOS DE BELEZA}

A atividade política de Jéssica - e, de certo modo, seu despertar para o tema racial e do racismo estrutural - se deu por meio da cosmética. Ela contou ter vivido um momento de epifania quando uma amiga da universidade a levou a uma loja de produtos de beleza especializada em pessoas de pela preta e cabelo crespo. Foi uma revelaçáo perceber, contemplando prateleiras com produtos feitos para o tipo de cabelo e pele que ela tem, como durante todos os anos de sua vida ela tinha sido silenciosamente forçada a se adaptar a modelos estéticos que vinham do corpo branco. As maquiagens para a pele branca e o ato de alisar o cabelo era naturalizado e praticamente universal entre as mulheres do bairro, evangélicas ou não.

Foi em uma loja de cosméticos e por meio do consumo que Jéssica enxergou sua condição de mulher negra e pobre - pobre por perceber que essa informação não estava disponível para ela até se tornar uma estudante universitária e passar a conviver com outras pessoas negras moradoras das áreas mais centrais de Salvador. E foi a partir desses instrumentos que negociou a construção de uma imagem nova para si, uma que ela não quis que fosse móvel como a da roupa, mas que continuasse permanentemente como um marcador de identidade.

Gradativamente, ao longo de meses, desde esse momento de descoberta ao entrar na loja de cosméticos, Jéssica foi recriando a maneira de tratar seus cabelos, passando do cabelo alisado com chapinha para o cabelo afro montado, grande e visível, que se colocava como um sinal da consciência de sua herança étnica, social e cultural. Essa atitude modernizante de Jéssica, uma mulher evangélica, também criou desconforto entre os participantes da igreja que frequentava. Por isso, a transformação aconteceu de maneira 
gradual, em fases intermediadas por períodos de dois ou mais meses, que dava tempo para que o estágio anterior de modificação de seu visual fosse aceito ou tolerado. Essa mudança de Jéssica, que também influenciou suas amigas, teve consequências fora da igreja. Ela foi uma das primeiras jovens do bairro a rejeitar o uso de técnicas de alisamento de cabelo e, a partir de seu exemplo, no âmbito local, outras mulheres jovens do bairro, evangélicas e não evangélicas, fizeram o mesmo percurso de adotar cortes de cabelo que explicitavam, em vez de esconderem, sua identidade e sua ascendência afro.

\section{CONSIDERAÇÕES FINAIS}

O tema do artigo de Vital da Cunha - evangélicos de esquerda e/ ou progressistas - não menciona de forma clara a importância que esse tópico terá para o Brasil, a começar pelo desfecho da eleição presidencial de 2022. Segundo dados recentes do DataFolha, mencionados anteriormente, evangélicos continuam sendo os principais apoiadores de Jair Bolsonaro. A ampliação da presença de vozes dissidentes questiona a ideia de que a bancada evangélica representa o mundo evangélico, dando oportunidades para outros candidatos - inclusive aqueles identificados com a esquerda e/ ou com visóes progressistas - dialogarem com evangélicos comuns, inclusive com aqueles que fazem parte das camadas populares, e não apenas com evangélicos que já pertencem ou transitaram entre as camadas médias via curso universitário.

Seguindo o caminho aberto por Vital da Cunha, esse artigo registrou e analisou dados etnográficos sobre evangélicos que se identificam como sendo de esquerda e/ou progressistas. Em vez de focar em candidatos e militantes que atuaram durante a eleiçáo de 2020, apresentei casos baseados nas experiências de evangélicos moradores de um bairro trabalhador, no extremo da área metropolitana de Salvador, onde, apesar das melhoras significativas na oferta de serviços de educação básica, a maior parte dos moradores não têm a perspectiva de continuar estudando depois do fim do ensino médio. 
Uma das diferenças entre a explicitação da identidade política de Heleno e Jéssica é que ele faz isso se referindo à política partidária. Seu interesse, inclusive como pastor batista, é baseado no entendimento de que o exemplo bíblico da vida e do pensamento de Jesus dialogam com a atuação política. Heleno está interessado na defesa de ideias que promovam a justiça social, conforme - em seu entendimento - foi a atuação de Jesus, simbolicamente compartilhando o pão, curando enfermos e valorizando os mais vulneráveis.

Jéssica, por sua vez, não fala espontaneamente de política partidária, mas desafiou o pastor e os adultos de sua igreja pelo direito de vestir calças compridas para ir à universidade - e náo a saia que a identificava como evangélica. Essa mudança - junto com a disponibilidade de serviços de rede social - abriu oportunidades para ela estabelecer relacionamentos fora do controle da igreja, com ativistas políticos do movimento negro em Salvador e com religiosos ligados a religiôes de matriz africana. Ela leva para a igreja debates sobre feminismo e sobre identidade racial sem relacioná-los a bandeiras de partidos políticos.

O caso de Heleno aponta para a limitação de debater o assunto político entre evangélicos não considerando as particularidades das organizaçôes religiosas. Como e por que as principais organizaçôes protestantes, e também de outras tradiçóes do cristianismo, ainda aparecem como focos importantes de apoio ao presidente Bolsonaro? Seria porque no contexto de uma "naçáo cristâ", Bolsonaro é o único candidato a defender a família tradicional em relaçấo às pautas morais como a proibiçáo do aborto, da maconha e casamento gay? $?^{12}$

${ }^{12}$ Este termo "nação cristã" foi aplicado por um pastor evangélico de origem latina durante uma entrevista para o jornal The New York Times, sobre o motivo para alguns evangélicos latinos seguirem declarando-se apoiadores do presidente Donald Trump, apesar da posiçáo de Trump ser contra a imigração, especialmente a de latino-americanos que chega ao país pela fronteira com o México (Medina, Jennifer. Latino, Evangelical and Politically Homeless. The New York Times, 11 Oct. 2020. Disponível em: www.nytimes. com/2020/10/11/us/politics/hispanic-evangelical-trump.html. Acesso em: 17 abr. 2021).

Debates do NER, Porto Alegre, ano 2 I, N. 39, P. 9 I-I i 8, Jan./Jul. 202 I 
O artigo de Vital da Cunha menciona evangélicos que "despertam" criticamente para o que eles consideram ser ambientes inibidores da crítica e do questionamento. Por isso se afastam dessas igrejas e, para manter suas identidades como cristãos, se vinculam a igrejas menores. $\mathrm{O}$ caso de Jéssica aponta para outras possibilidades de desfecho desses atritos que tendem a acontecer entre jovens cristãos, universitários e usuários ativos de serviços de comunicação online e os representantes mais conservadores de suas igrejas e de suas denominaçóes.

Jéssica e Heleno mostram um cenário complexo e híbrido, abrindo possibilidades para o fortalecimento de suas posiçôes via formação de redes de apoio. O caso de Heleno, especialmente, mostra a complexidade desse tema em relação à situação dos pastores ligados à Convenção Batista Brasileira (CBB), que sofrem pressão de dentro da organização, de seus pares e também de seus congregados para silenciar a defesa de pautas progressistas e/ou de esquerda em suas igrejas.

Da mesma maneira que o bolsonarismo se fortaleceu a partir do uso de ambientes privados de interlocução e em rede a partir de serviços de mídias sociais, esses evangélicos - pastores ou não - que não atuam diretamente na promoção de candidaturas políticas, têm encontrado novas possibilidades de resistência pela formação de grupos que se comunicam online e que reconhecem e fortalecem suas visóes e práticas críticas à imagem prevalecente hoje do evangélico conservador, que apoia o presidente Bolsonaro e vota segundo a recomendação de suas igrejas em candidatos da bancada evangélica. E mesmo considerando os esforços de lideranças para constranger e intimidar pastores com perspectivas à esquerda, as redes sociais, particularmente o Whats $A p p$, se torna uma ferramenta importante para núcleos de dissidentes se aproximarem e conversarem.

Esse artigo também sugere que o exame desse tema - evangélicos progressistas e/ou de esquerda - aconteça também considerando as diferenças que parecem existir em termos de atuação política entre pentecostais e representantes das igrejas históricas. 
A defesa das pautas morais - aborto, drogas e sexualidade - dificulta o diálogo entre grupos de esquerda e/ou progressistas e evangélicos, especialmente da tradição pentecostal, que são majoritariamente brasileiros das camadas populares. Em que medida a identidade de evangélico progressista ou de esquerda está disponível para a maioria dos evangélicos pobres, que não tiveram acesso à universidade, e que têm essas pautas morais como assuntos importantes? E como a definição sobre o significado do termo "progressista", por exemplo, pode interferir, restringindo ou ampliando o número de evangélicos das camadas populares que se identificam dessa maneira?

Heleno e Jéssica se identificam como evangélicos de esquerda e/ou progressistas, são vistos dessa forma por seus pares e também por outros evangélicos que se consideram e são considerados conservadores e seguem defendendo o governo de Bolsonaro. Mas fora do ambiente de suas igrejas, no contexto mais amplo, para pessoas que não são evangélicas e se identificam e são identificadas como sendo progressistas e/ou de esquerda, Heleno e Jéssica provavelmente não seriam vistos como representantes de ideias progressistas e/ou de esquerda se os critérios de avaliaçáo forem a defesa de pautas morais como a legalização do aborto, da comercialização da maconha e - do tema vago e confuso atualmente chamado - de "casamento gay" ${ }^{13}$. Isso sugere que ser ou não ser evangélico de esquerda e/ou progressista depende também da chancela de quem está fora das igrejas e que - geralmente - percebe o cristianismo evangélico de maneira superficial, desinformada e preconceituosa.

${ }^{13}$ Em 2017, acadêmicos pesquisaram os participantes da Marcha para Jesus e constataram, por exemplo, que esse grupo náo confia nos políticos e defende respeito aos homossexuais nas escolas. Ver https://goo.gl/2VbhCF.

Debates do NER, Porto Alegre, ano 2I, N. 39, P. 9 I-I I 8, JAN./JUl. 202 I 


\section{REFERÊNCIAS}

ALMEIDA, Ronaldo de. Deus acima de todos. In: ABRANCHES, S. et al. Democracia em risco? 22 ensaios sobre o Brasil hoje. São Paulo: Companhia das Letras. 2019.

ALMEIDA, Ronaldo. Bolsonaro's Religion. YouTube, Brazil LAB, Princeton University, 1 Oct. 2020. Disponível em: youtu.be/GagKP8xZylc. Acesso em: 17 abr. 2021.

ALVES, José Eustáquio Diniz. As Mulheres Evangélicas Pobres e a Eleição de Bolsonaro. EcoDebate (6 mar. 2019) Disponível em: http://www.ecodebate. com.br/2019/03/06/as-mulheres-evangelicas-pobres-e-a-eleicao-de-bolsonaro-artigo-de-jose-eustaquio-diniz-alves/. Acesso em: 17 abr. 2021.

ALVITO, Marcos. Nós contra o mundo. Pentecostais ajudam na inserção social dos mais pobres, mas criam uma guerra espiritual: fora da igreja só existe o diabo. Revista de História do Museu Nacional 87(8), p. 27-9, 2012. SPYER, Juliano. Midias Sociais No Brasil Emergente: Como a Internet Afeta a Mobilidade Social. EDUC / UCL Press, 2018.

ROSSI, Marina. Para Muitas Mulheres o Processo De Empoderamento Está Atrelado à Igreja. EL PAÍS, 14 May 2019. Disponível em: brasil.elpais. com/brasil/2019/05/11/politica/1557527356_335349.html. Acesso em: 17 abr. 2021.

Recebido em: 31/03/2021

Aprovado em: 31/03/2021

Debates do NER, Porto Alegre, Ano 2 I, N. 39, P. 9I-I I 8, JAn./Jul. 202 I 